\title{
A comparison of an effect of different anti-inflammatory drugs on human platelets
}

\author{
J. R. O'BRIEN, WENDY FINCH, AND ELIZABETH CLARK \\ From the Portsmouth and Isle of Wight Area Pathological Service, Milton Road, Portsmouth
}

SYNOPSIS Different doses of aspirin, indomethacin, paracetamol, benorylate, and sodiurfe salicylate were taken by four volunteers. The minimal dose that altered a platelet functio test and the persistence of this alteration at different dose levels were studied. Minute doses of indomethacin $(0.035 \mathrm{mg} / \mathrm{kg})$ were effective but the effect of even a large single dose did nof persist. A tenth of the therapeutic dose of aspirin $(1 \mathrm{mg} / \mathrm{kg})$ was effective, and higher doses altered the platelets' function for several days. Benorylate in a high therapeutic dose gave aspirin-like results. Paracetamol and sodium salicylate were relatively inactive. The persistencפ of the aspirin effect may be related to the acetyl group. These findings are surveyed in relation to a general theory of the action of anti-inflammatory drugs.

In 1963, Adams and Cobb reported that the erythema produced by rubbing thurfyl nicotinate onto human skin was inhibited by the prior ingestion of aspirin, and furthermore the effect persisted for days, yet a measurable level of aspirin in the blood was demonstrable for only about two hours. Recently, O'Brien (1968a) reported that some effects of aspirin on platelet function also persisted for days. This effect is the inhibition of the release of adenosine diphosphate (ADP) and serotonin (O'Brien, 1968a;Weiss, Aledort, and Kochwa, 1968; Zucker and Peterson, 1968). O'Brien (1968a) also claimed that 150 milligrams of aspirin $(2 \mathrm{mg} / \mathrm{kg})$ produced these effects, and that this was the smallest dose ever reported to have any pharmacological effect. Preliminary results with other anti-inflammatory drugs were also reported (O'Brien, 1968b).

The present study was intended to explore this situation further. What is the minimal dose of aspirin to have this effect on platelets? How far does dose level influence the curious persistence of this effect? Are other drugs equally active?

Received for publication 22 October 1969

\section{Method}

Four people aged 35-55 years, one man and three women, were selected because they were available and because they were known to have had ng previously observed periods of spontaneous lack of response to adrenaline (O'Brien, 1964). Each person had $10 \mathrm{ml}$ of blood withdrawn at 9.38 am after his or her normal light breakfast and. was then given orally a weighed amount of the pure drug under test. Further blood samples were withdrawn one and a half and six hous after taking the drug. Thereafter blood wass collected daily in the morning. The tests were carried out until the response returned to normas and usually several days then elapsed before further studies began. The smallest effective dose in each person was determined by giving decreas ing doses until the sample at one and a half hour was not abnormal. The persistence of the effectit of all doses was studied. A separate study w organized to see if continued medication pros duced a longer lasting effect. All the volunteers irrespective of their weight, took the same mode rate therapeutic dose of the drugs in tablet form 
repeatedly through a period of 48 hours. In this part of the study the last tablets were taken at $10 \mathrm{pm}$ and blood was collected 16 hours later during the following afternoon; thereafter blood was collected daily at the same time, ie, at 40 , 64 hours, etc, after ingesting the drug.

The drugs studied were aspirin, indomethacin, paracetamol, and benorylate. Sodium salicylate was also studied, but it was given to four other volunteers because by this stage of the study the haemoglobin level of the four original persons was beginning to drop as a result of the frequent venepunctures.

Five tests have previously been studied (O'Brien, 1968a), each of which was dependent on the release of ADP from platelets and was inhibited by aspirin. A test with adrenaline gave the most clear-cut results. Normally, following the addition of adrenaline to stirred plateletrich plasma there is a double wave of aggregation. After the ingestion of aspirin or the addition of aspirin in vitro to platelet-rich plasma the first wave of aggregation is normal but the second wave of aggregation does not occur. Such plasma will be called 'unresponsive'. Accordingly, $10 \mathrm{ml}$ of blood from the venepuncture was added to $1.0 \mathrm{ml} 3.5 \%$ sodium citrate and immediately centrifuged at 1,000 rpm for 15 minutes to produce platelet-rich plasma; without delay $2 \mathrm{ml}$ of the plasma was then transferred to the cuvette of the nephelometer for measuring platelet aggregation as previously described (O'Brien, Heywood, and Heady, 1966). After two minutes for warming to $37^{\circ} \mathrm{C}, 0.1 \mathrm{ml}$ of a freshly prepared adrenaline solution to give a final concentration $5 \mathrm{M} \times 10-7$ was added to the stirred platelet-rich plasma. The 'delay' in seconds as previously defined is reported. It is reported as long, if, after the addition of adrenaline, $5 \mathrm{M} \times 10-4$ final concentration, there was no second wave of aggregation within three minutes after the end of the first wave.

\section{Results}

Table I reports the results both of the singledose trials and those when a therapeutic dose was given repeatedly for $\mathbf{4 8}$ hours. Sodium salicylate was given to four other volunteers at a dose level of $10 \mathrm{mg} / \mathrm{kg}$; two volunteers gave abnormally long delays at one and a half hours but had returned to normal at six hours. The other two

\begin{tabular}{|c|c|c|c|c|c|c|}
\hline \multirow[t]{2}{*}{ Subject } & \multicolumn{5}{|c|}{ Aspirin (single dose trial $\mathrm{mg} / \mathrm{kg}$ ) } & \multirow{2}{*}{$\begin{array}{l}\text { Repeated Dose over } \\
48 \text { Hours (mg) } \\
4,200\end{array}$} \\
\hline & $0 \cdot 3$ & 0.6 & $1 \cdot 2$ & 1.8 & $12 \cdot 7$ & \\
\hline $\begin{array}{l}\mathbf{A} \\
\mathbf{B} \\
\mathbf{C}\end{array}$ & $\begin{array}{r}28,35 \\
5,10\end{array}$ & $\begin{array}{l}10, X, 40 \\
40, X, X, 40 \\
(50,46) \\
(24,24)\end{array}$ & $\begin{array}{l}40, X, X, X, X, 50 \\
25, X, X, 28 \\
25, X, 26,30\end{array}$ & $\bar{z}$ & $\begin{array}{l}\text { 42, X, X, X, X, X, X, X, } 35 \\
0, X, X, X, X, X, 35 \\
65, X, X, X, X, 46\end{array}$ & $\begin{array}{l}\mathbf{X}, \mathbf{X}, \mathbf{X}, \mathbf{X}, \mathbf{X}, 30 \\
\mathbf{X}, \mathbf{X}, 60 \\
\mathbf{X}, \mathbf{X}, \mathbf{X}, 64\end{array}$ \\
\hline D & & 40,20 & 20,50 & $0, X, X, X, 160$ & $15 X, X, X, X, 30$ & $\mathrm{X}, \mathrm{X}, \mathrm{X}, 44$ \\
\hline
\end{tabular}

Table Ia Effect of aspirin on the 'delay' in adrenaline-induced aggregation ${ }^{1}$

Subject Indomethacin (single dose trial $\mathrm{mg} / \mathrm{kg}$ )

Repeated Dose over 48 Hours

\begin{tabular}{|c|c|c|c|c|c|c|c|}
\hline 0.02 & 0.035 & $0 \cdot 07$ & $0 \cdot 15$ & $0 \cdot 3$ & 0.6 & $l \cdot 2$ & 275 \\
\hline $\begin{array}{l}\overline{50,104} \\
10,20\end{array}$ & $\begin{array}{l}\overline{67}, X, X, 52 \\
0,40\end{array}$ & $\begin{array}{l}38,60 \\
5, X, 10 \\
(26, X, 30) \\
(30, X, 54)\end{array}$ & $\begin{array}{l}60, x, 50 \\
60, x, 80\end{array}$ & $\begin{array}{l}130, X, X, 20 \\
0, X, 5 \\
30, X, X, 22\end{array}$ & $\begin{array}{l}50, X, X, 60 \\
46, X, X, 27 \\
10, X, 60\end{array}$ & $\begin{array}{l}50, x, x, 44 \\
40, x, X, 36 \\
20, x, 20\end{array}$ & $\begin{array}{l}x, x, 20 \\
x, 40 \\
44\end{array}$ \\
\hline 0,50 & 10,30 & $40, X, 28$ & - & $22, X, 20$ & $10, X, 30$ & $20, x, x, 30$ & 40 \\
\hline
\end{tabular}

Table Ib Effect of indomethacin on the 'delay' in adrenaline-induced aggregation ${ }^{1}$

\begin{tabular}{|c|c|c|c|c|c|c|}
\hline \multirow[t]{2}{*}{ Subject } & \multicolumn{2}{|c|}{$\begin{array}{l}\text { Paracetamol } \\
\text { (single dose trial } \mathrm{mg} / \mathrm{kg} \text { ) }\end{array}$} & \multirow{2}{*}{$\begin{array}{l}\text { Repeated D over } 48 \text { Hours }(\mathrm{mg}) \\
8,000\end{array}$} & \multicolumn{2}{|c|}{ Benorylate (single dose trial $\mathrm{mg} / \mathrm{kg}$ ) } & \multirow{2}{*}{ Repeated Dose over 48 Hours (mg) } \\
\hline & $6 \cdot 0$ & 30 & & $17 \cdot 0$ & $36 \cdot 0$ & \\
\hline $\begin{array}{l}\mathbf{A} \\
\mathbf{B} \\
\mathbf{C} \\
\mathbf{D}\end{array}$ & $\begin{array}{l}50, x, 40 \\
26,26 \\
25,48 \\
60,5\end{array}$ & $\begin{array}{l}40, X, 40 \\
20,30 \\
30,7 \\
25,44\end{array}$ & $\begin{array}{l}X, 60 \\
X, 10 \\
60 \\
20\end{array}$ & $\begin{array}{l}50,40 \\
20,10 \\
20,60 \\
36,42\end{array}$ & $\begin{array}{l}30, X, X, X, X, X, 35 \\
0, X, X, X, 25 \\
24, X, X, 50 \\
40, X, X, 5\end{array}$ & $\begin{array}{l}\mathbf{X}, \mathbf{X}, \mathbf{X}, \mathbf{X}, \mathbf{8 2} \\
\mathbf{X}, \mathbf{X}, \mathbf{3 0} \\
\mathbf{X}, \mathbf{X}, \mathbf{4 0} \\
\mathbf{X}, \mathbf{X}, \mathbf{4 0}\end{array}$ \\
\hline
\end{tabular}

Table Ic Effect of paracetamol and benorylate on the 'delay' in adrenaline-induced aggregation ${ }^{1}$

'The figures record the delay in seconds. A long delay, ie, complete inhibition, is indicated by $\mathbf{X}$. For each dose the first figure re- $O$ ported is the control pretreatment result. The second figure is the response after one and a half hours; the third after six hours; the fourth that after 24 hours, the fifth that after 48 hours, and so on. In the columns relating to the trial of repeated medication for 48 for hours, the first figure is that obtained 16 hours after the last tablet, the second that 40 hours after, third 64 hours after, and so on. Bracketed figures indicate repeated studies. 
were unaffected. Table II gives some mean figures.

Since the results were obtained from four people only, and from four other volunteers in the sodium salicylate tests, they may not be valid for the population as a whole. However, although there was rough agreement between individuals, there also seem to be personal differences of sensitivity to these drugs, irrespective of the drug used. Thus, volunteer A usually responded to a smaller dose and the effect lasted longer, and D usually responded least well of the four.

The minimal effective dose is used here to indicate the least dose (in a twofold dosage scale) that produces a long (greater than 180 second) delay in three out of the four volunteers when tested one and a half hours after taking the drugs. The minimal effective dose for indomethacin was $0.07 \mathrm{mg} / \mathrm{kg}$ : $0.035 \mathrm{mg} / \mathrm{kg}$ produced a long delay in one person, and even a dose of $0.02 \mathrm{mg} / \mathrm{kg}$ prolonged the delay from 50 to 104 seconds, which may indicate partial inhibition. The minimal effective dose for aspirin was $1 \cdot 2$ $\mathrm{mg} / \mathrm{kg}$ and that for benorylate would fall between 17 and $36 \mathrm{mg} / \mathrm{kg}$. Paracetamol was almost inactive and sodium salicylate at a dose of $10 \mathrm{mg} / \mathrm{kg}$ produced long results in two out of four volunteers at one and a half hours only.

The approximate mean maximum duration of the effect showed striking differences between the different drugs tested. The effect of aspirin persisted on average for over three days and in one person for upwards of five days, and the persistence of the effect was clearly dose-dependant. The effect of indomethacin was always short lived; however big the dose, inhibition was never detected after six hours. Furthermore there was no evidence that the duration of the effect of indomethacin depended on the dose given; indeed, the smallest effective dose $(0.035 \mathrm{mg} / \mathrm{kg})$ persisted for six hours. The effect of benorylate at the high dose of $36 \mathrm{mg} / \mathrm{kg}$ persisted for many hours, but may be less long lasting than that of aspirin. The duration of the effect of paracetamol and sodium salicylate appeared to be short on the few occasions when they had any effect at all.

Ingestion of the drugs over a period of 48 hours did not lead to a further prolongation of the effect except in the case of indomethacin. In two people any effect had disappeared by 16 hours when the first samples were withdrawn.
In one the effect persisted for 16 hours and $\frac{\rho}{67}$ another for $\mathbf{4 0}$ hours, which are longer times thai were observed in all the single dose studies.

\section{Discussion and Conclusions}

It will be seen that each of these drugs diffe $\frac{5}{8}$ in the detailed characteristics of its effect on platelets. Indomethacin is active in minute dosests but the effect of higher single doses does net persist, although the duration of the effect may be slightly increased by prolonged ingestio $\overrightarrow{B_{3}}$ The minimal effective dose of aspirin is abos? 17 times that of indomethacin and with higher doses the effect persists for several days. Benoryid ate in relatively high doses is effective, and the effect persists. Sodium salicylate and paracetamin are almost inactive.

The recommended single clinical dose varies somewhat for the condition under treatment, but approximate figures have been given in Tab II. It will be seen that both indomethacin an aspirin are effective in the platelet test at abogt a twelfth of the clinical dose. Benorylate effective in a single dose at about the clinical dose recommended $(15 \mathrm{mg} / \mathrm{kg})$. Paracetamol ar sodium salicylate are largely inactive even after a therapeutic dose.

The differences in the amount of drug require may reflect either possible differences in the avidity with which the drug is taken up by the relevant site or their effectiveness when absorbe on the site: this study does not distinguish between these two possibilities. Persistence of a drug induced effect may be due to the degree of petmanence at the bond between the drug and the site. Alternatively the drug could disorganize $a$ structure, eg, a membrane, and then disappeañ; recovery of normal function would then depent on the rate of resynthesis of the damaged struceture, and presumably this rate would be constang. The present findings support the former proposi tion. Each of these drugs probably acts finally through a similar mechanism, so that the differe rates of recovery observed suggest differem degrees of binding and not different rates of resynthesis.

Since acetyl salicylate is active and sodium salicylate is almost inactive, it has been suggested

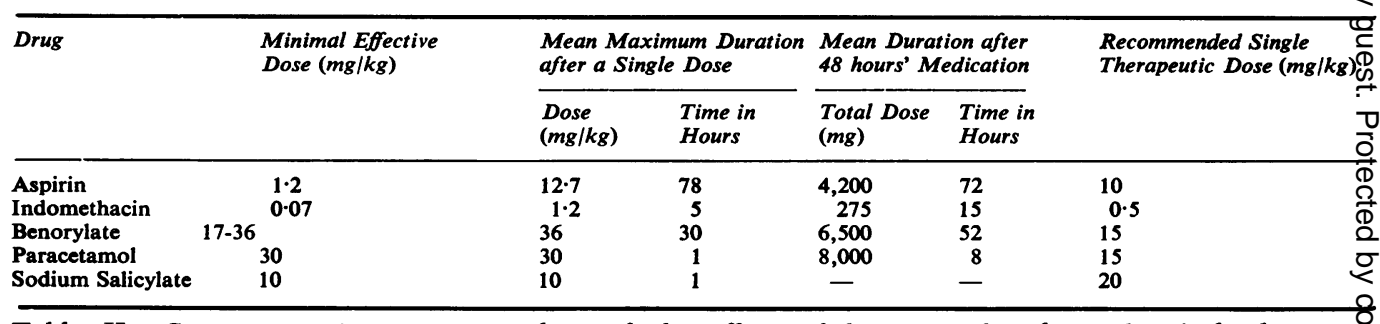

Table II Some approximate mean values of the effects of drugs on adrenaline-induced platelet aggrẹg gation 
that the acetyl group is of importance (Youssef and Barkhan, 1969). Indomethacin contains no acetyl group but it is the most active drug, even though the effect is short lived. Thus an acetyl group cannot determine this immediate activity. However, the persistence of the effect may be related to an acetyl group. The effect of aspirin persists longest and aspirin has a labile acetyl group. The benorylate effect also persists, but not for so long and benorylate has a tightly bound acetyl. The indomethacin effect does not persist and this drug has no acetyl group. The partition coefficients of these drugs between water and a number of organic solvents have been studied (Robertson, personal communication) and none seem related to the effect on platelets.

Collier (1969) has pointed out that the pharmacological potency of aspirin relative to that of sodium salicylate differs markedly in different test situations. The present findings suggest that the inhibition of the release reaction following platelet aggregation falls into the group of situations, including the inhibition of bronchospasm in guinea-pigs (Berry and Collier, 1964), the inhibition of the release of rabbit aorta contracting substance (Piper and Vane, 1969), and of the delay of skin erythema induced by thurfyl nicotinate (Adams and Cobb, 1963). In all these situations aspirin is highly effective and sodium salicylate almost inactive.

Most aspirin effects are short lived but Adams and Cobb (1963) reported an effect that persisted for days and long after the blood level had returned to normal; accordingly it seems likely that there is some, at present unknown, connexion between the effects studied by Adams and those reported here.

The present results are relevant to any general concept of how the anti-inflammatory drugs act. Collier (1969) proposed that 'aspirin and like acting drugs block a route leading to or from specific receptors'. He also suggested that 'such a mechanism might be envisaged as one transferring mediators across cellular or other boundaries; alternatively, the release of an intermediary substance might be susceptible to aspirin blockade.' With platelets several antiinflammatory drugs have now been reported to inhibit the release reaction (O'Brien, 1968a; Weiss et al, 1968; Zucker and Peterson, 1968), to inhibit the release of a soluble platelet factor 4 (Youssef and Barkhan, 1969) and a membranebound heparin neutralizing activity ( $O$ 'Brien, Finch, and Clark, 1970), and they also inhibit platelet factor 3 (Weiss et al, 1968; Zucker and Peterson, 1968) as well as secondary platelet aggregation. They inhibit the escape of haemo $\frac{\varrho}{\overline{5}}$ globin from red cells following various insults (Brown and Mackey, 1968; Inglot and Wolna 1968). These many phenomena with differene drugs and different cells suggest that all these: anti-inflammatory drugs have a similar effect on ${ }^{\frac{\rho}{+}}$ the cell membrane which has been called 'mem? brane stabilization' (Seeman, 1966). It follows that certain pharmacological effects of these drugs may also be due to a similar type of protective stabilization of a membrane in the cell

The essential part of the volunteers is acknow ledged with gratitude. We thank Dr H. O. J? Collier for helpful criticism. A grant to J.R.O.B N from the Wellcome Trust is gratefully acknowio ledged. Drugs were kindly supplied by Mercke Sharp \& Dohme Ltd and Winthrop Laboratories.

References

Adams, S. S., and Cobb, R. (1963). In Salicylates: An Internationa Symposium, edited by A. St. J. Dixon, B. K. Martin M. J. H. Smith, and P. H. N. Wood, p. 127. Churchill? London.

Berry, P. A., and Collier, H. O. J. (1964). Bronchoconstrictoraction and antagonism of a slow-reacting substance fromco anaphylaxis of guinea-pig isolated lung. Brit.J. Pharmacol. 23, 201-216.

Brown, J. H., and Mackey, H. K. (1968). Further studies on the erythrocyte anti-inflammatory assay. Proc. Soc. exp. 웅 Biol. (N.Y.), 128, 504-509.

Collier, H. O. J. (1969). New light on how aspirin works. Nature (Lond.), 223, 35-37.

Inglot, A. D., and Wolna, E. (1968). Reactions of non-steroidalo anti-inflammatory drugs with the erythrocyte membrane. $(\mathcal{D}$ Biochem. Pharmacol., 17, 269-279.

O'Brien, J. R. (1964). Variability in the aggregation of human platelets by adrenaline. Nature (Lond.), 202, 1188-1190.

O'Brien, J. R. (1968a). Effects of salicylates on human platelets? Lancet, 1, 779-783.

O'Brien, J. R. (1968b). Effect of anti-inflammatory agents on platelets. Lancet, 1, 894-895.

O'Brien, J. R., Finch, W., and Clark, E. (1970). Platelet bound: and soluble platelet factor $4:$ effects of aggregating agents, $\frac{\sigma}{3}$ of aggregation and of aspirin. Proc. Soc. exp. Biol. (N.Y. (In the press.)

O'Brien, J. R., Heywood, J. B., and Heady, J. A. (1966). TheO quantitation of platelet aggregation induced by four compounds: a study in relation to myocardial infarction. 0 Thrombos. Diathes. haemorrh. (Stuttg.), 16, 752-767.

Piper, P. J., and Vane, J. R. (1969). Release of additional factors $D$ in anaphylaxis and its antagonism by anti-inflammatory음 drugs. Nature (Lond.), 223, 29-35.

Robertson, A. Personal communication.

Seeman, P. (1966). Erythrocyte membrane stabilization by local anaesthetics and tranquilizers. Biochem. Pharmacol.,N 15, 1753-1766.

Weiss, H. J., Aledort, L. M., and Kochwa, S. (1968). The effect of salicylates on the hemostatic properties of platelets $\sigma$ in man. J. clin. Invest., 47, 2169-2180.

Youssef, A. H., and Barkhan, P. (1969). Inhibition by aspirine of release of antiheparin activity from human platelets. Brit. med. J., 3, 394-396.

Zucker, M. B., and Peterson, J. (1968). Inhibition of adenosine? diphosphate-induced secondary aggregation and other $\square$ platelet functions by acetylsalicylic acid ingestion. Proc. $\bar{O}$ Soc. exp. Biol. (N.Y), 127, 547-551. 